\title{
Inclusión educativa desde la óptica de los académicos responsables de la formación de profesores de la Universidad Católica del Maule - Chile
}

\author{
JUAN CORNEJO ESPEJO \\ Universidad Católica del Maule - Chile \\ Recibido el 09-11-16; primera evaluación el 11-10-18; \\ segunda evaluación el 05-02-19; tercera evaluación el \\ 13-02-19; aceptado el 14-02-19
}

\section{RESUMEN}

El artículo, resultados de un estudio realizado con académicos formadores de profesores de la Universidad Católica del Maule (UCM), a los cuales se les aplicó una encuesta sobre la base de una escala Likert, busca develar sus opiniones en relación con la inclusión educativa, las vinculaciones que establecen entre necesidades educativas especiales (NEE) e inclusión, el reconocimiento de otros grupos objeto de exclusión y/o discriminación en los sistemas escolares, los nudos críticos que supone la atención de algunos de estos grupos y las posibilidades de formación que ofrece su institución universitaria en este campo. Entre los principales hallazgos destaca la ampliación de las ideas de inclusión que, a juicio de estos académicos, se ha traducido en la preocupación por otros grupos objeto de exclusión, no limitándose a la atención de estudiantes con NEE. Además, concluyen que los futuros profesores formados por la UCM, si bien se muestran sensibles a la temática, aún no cuentan con las competencias suficientes para implementar proyectos inclusivos efectivos y herramientas para trabajar con comunidades escolares diversas.

Palabras clave: formación de profesores, inclusión, opiniones y competencias

\footnotetext{
* Bachiller en Teología por la Pontificia Universidad Católica de Río de Janeiro, Brasil. Magister en Ciencias Sociales por el Instituto Latinoamericano de Doctrina y Estudios Sociales (ILADES), Chile. Magíster en Historia de América por la Universidad de Santiago de Chile. Magíster en Ciencia Política, Mención Relaciones Internacionales por la Pontificia Universidad Católica de Chile. Magíster en Educación por la Universidad de Santiago de Chile. Doctor en Ciencia Política por el Instituto Universitario de Pesquisas de Río de Janeiro, Brasil. Doctor en Estudios Americanos, Mención Pensamiento y Cultura por la Universidad de Santiago de Chile. Correo electrónico: jcornejo@ucm.cl
} 
Educational inclusion from the perspective of the academics responsible for teacher training at the Universidad Católica del Maule - Chile

\section{Abstract}

The article, the results of a study carried out with academic teacher educators of the Universidad Católica del Maule, to which a survey was applied based on a Likert scale, seeks to reveal their opinions in relation to educational inclusion, the links that establish between NEE and inclusion, the recognition of other groups that are subject to exclusion and / or discrimination in school systems, the critical knots involved in the attention of some of these groups and the training possibilities offered by their institution in this field. Among the main findings are the expansion of inclusion ideas that, in the opinion of these academics, has resulted in concern for other groups subject to exclusion, not limited to the care of students with NEE. In addition, they conclude that the future teachers trained by the Universidad Católica del Maule, although they are sensitive to the subject, do not yet have sufficient competences to implement effective inclusive projects and tools to work with diverse school communities.

Keywords: teacher training / inclusion / opinions / competences

Inclusáo educacional na perspectiva dos acadêmicos responsáveis pela formação de professores da Universidad Católica del Maule - Chile

\section{Resumo}

$\mathrm{O}$ artigo, resultado de um estudo realizado com acedêmicos formadores de professores da UCM aos quias lhes foi aplicada uma encuesta com base em uma escala Likert, busca revelar suas opinióes em relação à inclusão educacional, os vínculos estabelecidos entre NEE e inclusão, o reconhecimento de outros grupos sujeitos à exclusão e / ou discriminação nos sistemas escolares, os nodos críticos que supóe a atenção de alguns destes grupos e as possibilidades de formação que oferece a Universidade neste campo. Entre os principais achados está a ampliação das ideias de inclusão que, na opinião desses acadêmicos, se tem traduzido em preocuapaçấo por outros grupos objeto de exclusão, não se limitando ao atendimento de estudantes com NEE. Além disso, concluem que os futuros professores formados pela UCM, embora sejam sensíveis ao assunto, ainda não possuem competências suficientes para implementar projetos inclusivos eficazes e ferramentas para trabalhar com comunidades escolares diversas..

Palavras chave: formação de professores / inclusão / opiniôes / competências 
Inclusión educativa desde la óptica de los académicos responsables de la formación...

\section{INTRODUCCIÓN}

El presente artículo tiene como objetivo mostrar las percepciones y actitudes de los responsables de la formación de profesores de la Universidad Católica del Maule - Chile (UCM) en relación con la inclusión educativa; es decir, develar sus ideas en torno al tema, las vinculaciones que establecen entre necesidades educativas especiales $(\mathrm{NEE})^{1}$ e inclusión ${ }^{2}$, el reconocimiento que hacen de otros grupos objeto de exclusión y/o discriminación en los sistemas escolares, los nudos críticos que identifican en la atención de algunos de estos

1 El concepto aparece por primera vez en 1978 en el Informe Warnock y alude a una forma de entender y trabajar las dificultades o barreras que enfrentan los y las estudiantes para aprender y participar del currículo escolar (Ministerio de Educación [Mineduc], 2012). Dichas barreras pueden ser de distinto tipo: discapacidades y deficiencias identificables; dificultades de aprendizaje no atribuibles a alguna discapacidad o deficiencia; y dificultades debidas a desventaja socioeconómica, cultural o lingüística. En virtud de lo anterior, se espera que los y las estudiantes con NEE puedan superar las barreras de aprendizaje recibiendo las ayudas y recursos especiales que necesiten, ya sea de forma temporal o permanente, al interior del centro educativo regular (Mineduc, 2013). A su vez, se entiende por estudiante con NEE a aquel que precisa ayudas y recursos adicionales, ya sean humanos, materiales o pedagógicos, para conducir su proceso de desarrollo y aprendizaje, y contribuir al logro de los fines educativos (LGE 20.370, 2009, art. 23). Por otro lado, el concepto NEE implica una transición en la comprensión de las dificultades de aprendizaje, desde un modelo centrado en el déficit hacia un enfoque propiamente educativo, situando la mirada no solo en las características individuales de los estudiantes, sino más bien en el carácter interactivo de las dificultades de aprendizaje (Mineduc, 2015).

2 Directamente relacionado con las NEE tenemos la inclusión, la cual deriva del vocablo latino inclusio o inclusionis que no es otra cosa que el intento de que todos los individuos y grupos sociales, sobre todo aquellos que se encuentran en condiciones de segregación o marginación, puedan tener las mismas posibilidades y oportunidades de realizarse como individuos. Esto es, la inclusión se formula como solución al problema de la exclusión que es causada por circunstancias como la pobreza, el analfabetismo, la segregación étnica o religiosa entre otras cosas. De allí, que numerosos autores postulen que corresponde al Estado a través de sus distintas instituciones y organismos implementar planes y políticas para corregir estas situaciones, además de promover el bienestar e inclusión social (Sawaia, 1999).

En lo que respecta a la inclusión educativa, cabe destacar que, pese a no existir una definición única dado el carácter polisémico y las múltiples interpretaciones que de ella se derivan, puede ser entendida como un proceso continuo y en constante revisión, preocupado en transformar el sistema educativo y, en consecuencia, las instituciones, para privilegiar un aprendizaje de calidad y la participación de todos los estudiantes (Ainscow, Booth y Dyson, 2006; Echeita, 2009; Onrubia, 2009; Artiles y Kozleski, 2014; y Sampedro y McMullin, 2015; Verdugo, Amor, Fernández, Navas y Calvo, 2018). Asimismo, no se puede obviar que la inclusión educativa es un concepto propio de la pedagogía, que plantea que la escuela debe ser capaz de incluir a todos los individuos en el proceso educativo, sin importar su condición, origen, religión, raza, religión o género. Para la inclusión educativa, la inclusión es un valor positivo dentro de la escuela. Entiende que todos somos diferentes e independientemente de nuestras características individuales (físicas, psicológicas, sociales o culturales) y, por tanto, tenemos el mismo derecho a recibir una educación de calidad, pues, el fin último de ella es lograr el bienestar individual y social de todos los sujetos que participan dentro del sistema de educación formal (Devalle de Rendo y Vega, 2006). 
grupos y las posibilidades de formación que visualizan en su propia casa de estudios.

Atendiendo a ese propósito resulta fundamental situar el estudio en el contexto de la legislación chilena, y los debates y controversias que ha generado el actual proceso de reforma educacional en marcha en el país que, entre otras metas, se ha propuesto impulsar una serie de transformaciones tendientes a garantizar el acceso de todos los estudiantes, sin importar su origen, extracción socioeconómica u otra condición a una educación pública, gratuita y de calidad (Aguerrondo, 2008; Mineduc, 2016; Manghi, Saavedra, y Bacunán, 2018 ).

En este sentido, como es sabido, el sistema educacional chileno es uno de los más segregadores del mundo (García Huidobro, 2007; Unesco 2011, 2012; Unicef, 2012, Educación 2020, 2017), razón por la cual la citada reforma pretende introducir una serie de medidas de orden legal, administrativas y pedagógicas con el propósito de promover una mayor integración social, cultural y académica de todos los estudiantes. Iniciativas, que al menos en términos teóricos, deberían verse reflejadas progresivamente en una matrícula más heterogénea en las escuelas y liceos públicos del país.

Lo anterior, inevitablemente, plantea nuevos desafíos a los establecimientos, especialmente en la generación de instituciones más inclusivas. Con todo, un acceso más equitativo no asegura por sí mismo el despliegue de prácticas educativas que atiendan adecuadamente la heterogeneidad.

En esta misma línea, no se puede obviar tampoco que la formación inicial y continua de profesores en Chile no ha enfatizado ni incentivado el desarrollo de competencias docentes para trabajar con grupos heterogéneos desde una perspectiva inclusiva. Como resultado de ello, muchas veces las prácticas pedagógicas e institucionales, lejos de eliminar las barreras que generan la exclusión de grupos de estudiantes, tienden a reproducirlas y naturalizarlas.

En lo que respecta a las universidades formadoras de profesores desafío no menor, representa el intento de ecuacionar programas de formación de profesores para la diversidad con la tendencia generalista predominante, claramente perceptible en los perfiles profesionales (Arroyo, 2008). Lo cierto es que no habría problema en ello, si esa generalización garantizase el acceso y la permanencia exitosa de todos los estudiantes en el sistema escolar por medio de prácticas curriculares diversificadas y ajustadas a los diferentes ritmos e intereses de aprendizaje (Tenorio, 2011; Valladares, 2013; Santos y Moreira, 2014; Ocampo, 2014). Sin embargo, lo que suele ocurrir es la organización de un currículo que capacita a los profesores para hacer clases en cualquier escuela y a distintos tipos de personas sin consideración a sus diferencias y 
singularidades, sometiéndolos a todos a un proyecto único de docencia y formación. Es decir, cuando se concibe el currículo como único y obligatorio, la diferencia queda condicionada no a una perspectiva universal en el sentido de ser derecho de todos, sino a la homogeneización de culturas y prácticas, como si «todos» representase una única forma de ser, y no a la diversidad (Santos y Moreira, 2014).

Considerando las exigencias que pesan sobre las instituciones formadoras de profesores, cabe preguntarse cuál es la perspectiva y énfasis dado a la inclusión educativa por estas instituciones, contenido tanto en los perfiles profesionales declarados, como en sus propias prácticas de aula y en las percepciones de sus académicos responsables de la formación docente (Manghi, Saavedra y Bacuñán, 2018).

El estudio, que a continuación se presenta, focalizado en este último estamento, es resultado de una investigación realizada sobre la base de una encuesta, especialmente construida para ese propósito, aplicada a los formadores de formadores de la UCM. Estudio que es complementario con otro de corte cualitativo, llevado a cabo con esos mismos profesionales referido al tema publicado en la revista Educação em Questão (Cornejo, 2016).

Es importante consignar, además, que la elección de la citada universidad responde a que ella es regional, confesional católica, parte de las denominadas universidades chilenas tradicionales, miembro del Consejo de Rectores (CRUCH) y de la Red de Universidades Públicas no Estatales G9, situada en la región del Maule, que privilegia la formación de profesores; siendo las pedagogías en conjunto no solo las que concentran el mayor número de estudiantes, sino el mayor desarrollo institucional en programas de posgrado e investigación.

Los estudiantes que atiende esta institución, especialmente los de pedagogía, provienen fundamentalmente de las zonas rurales del Valle Central y de las ciudades aledańas que prestan servicios a ese mismo sector de la economía nacional.

Básicamente, se trata de estudiantes cuyas familias, directa o indirectamente, están ligadas a las actividades agrícolas, pertenecientes a los segmentos más pobres, según datos de la misma institución, y que en más de un $70 \%$ son primera generación que ingresa a la universidad ${ }^{3}$.

3 Según datos aportados por la Dirección de Planificación y Desarrollo Universitario (DPDU). 


\section{MarCo teórico}

\subsection{Marco legal de inclusión educativa en Chile}

El marco regulatorio que establece las condiciones y garantías, de acuerdo a las cuales debe funcionar la educación especial en Chile, es la Ley General de Educación 20.370/ 2009 (Biblioteca del Congreso Nacional de Chile, 2009), la cual en su artículo 23 define los servicios, recursos humanos, técnicos, conocimientos especializados y ayudas que permiten atender las NEE que puedan presentar algunos estudiantes de manera temporal o permanente a lo largo de su escolaridad como consecuencia de un déficit o una dificultad específica de aprendizaje.

En ese mismo articulado, se establecen también las adecuaciones curriculares necesarias, como los requerimientos que demandan los procesos educativos interculturales o los que se llevan a cabo en hospitales, cárceles u otros centros educativos distintos a las escuelas convencionales; así como las condiciones de la educación intercultural bilingüe que busca garantizar el reconocimiento de la diversidad cultural y étnica del país.

No obstante, esto último, los mayores avances se verifican en el ámbito de la educación especial. Indudablemente, hay un gran trecho recorrido entre las nociones de «idiota», «imbécil» o «mongólico», predominantes durante el siglo XIX y primeras décadas del siglo XX, que enfatizaban la condición clínica de la persona («medicalización»), pasando por la noción de «retardo mental», a la noción de NEE, cuyo acento está en cierta clase de dificultades de aprendizaje, cualquiera que estas sean, que evidencian algunos estudiantes; es decir, las ayudas pedagógicas o servicios que requiere el estudiante para el logro de sus fines educativos (Godoy, Meza y Salazar, 2004; Paineo, 2012).

Con todo esto, no se puede desconocer que en otros ámbitos del sistema educativo nacional, que escapan a la educación especial, ha tendido a predominar la homogeneización ${ }^{4}$ y la asimilación ${ }^{5}$, particularmente de estudiantes

\footnotetext{
4 La homogeneización puede ser entendida como el proceso que minimiza o invisibiliza las diferencias y que en el ámbito pedagógico implica la negación de las diferencias individuales presentes en la escuela. "(...) había que considerar a cada uno como el todo y a todos como si fueran uno. Aquello que no lograban formar parte de la concepción imperante del todos estaban condenados al desvío, a la enfermedad o el destierro: alumnos irrespetuosos, peligrosos, inadaptados, indisciplinados, amanerados, hiperkinéticos, negros, pobres; docentes subversivos, demasiado antiguos, demasiado modernos, raros, etc.» (Narodowski, 1999, pp. 23-24).

5 La asimilación cultural es el proceso de integración de un grupo etnocultural (migrantes, grupos étnicos minoritarios, indígenas, etc.) inmersos o en contacto con una comunidad dominante. En este proceso, el grupo que es absorbido pierde por lo general su originalidad de manera parcial o total,
} 
provenientes de grupos étnicos minoritarios, indígenas o migrantes (Cornejo, 2012a, 2012b, Williamson y Coliñir, 2015).

Otro de los avances recientes en materia legal ha sido la promulgación de la Ley de Inclusión Escolar 20.845 / 2015 que garantiza la gratuidad y elimina el lucro en los establecimientos que reciben subvención del Estado, además, de terminar con la selección de estudiantes por medio de un sistema de admisión inclusivo y defender el derecho de los estudiantes a no ser expulsados arbitrariamente. Pese a lo ambicioso de la Ley, son numerosas las críticas que ha recibido, pues no profundiza en las implicancias y requerimientos de una educación inclusiva en el contexto de comunidades educativas diversas. Vale decir, no tematiza los desafíos que supone ampliar el horizonte de la inclusión de modo de no restringirla a los estudiantes con NEE e incluir a otros grupos tradicionalmente marginados o excluidos de los sistemas escolares formales: indígenas, minorías étnicas, migrantes, disidentes sexuales y/o de género, etc. Asimismo, de no establecer las condiciones para la formación de profesores o las competencias que estos profesionales requieren para una atención adecuada de esa diversidad (Ainscow, 2009; Infante, 2010; Valladares, 2013; GarcíaBarrera, 2017; Manghi, Saavedra y Bacuñán, 2018). En ese sentido, la ley no avanzó mucho en una conceptualización amplia de inclusión educativa, ni tampoco en asegurar que todos los establecimientos del país, no importando si son públicos o privados, efectivamente, desarrollen proyectos inclusivos que busquen erradicar toda forma de exclusión.

Es más, el propio Plan Nacional de Educación (2017) señala algunos ajustes que requiere la ley. Por lo pronto, contrarrestar la segregación educativa imperante a través de un sistema de información sobre la misma Ley, además de las necesarias reformas administrativas y financieras. Sin embargo, como subraya el mismo Plan, reducir las limitaciones de la Ley a la segregación socioeconómica presente en las escuelas es insuficiente, haciéndose necesario el diseño de herramientas que permitan abordar la diversidad desde distintas perspectivas (de género, culturales, territoriales y etarias).

En sintonía con lo anterior, el Plan propone, además, el fortalecimiento de las comunidades educativas, el apoyo a los estudiantes con NEE reformulando el Programa de Integración Escolar (PIE), la creación de centros especializados

como sus maneras de hablar, su lengua o dialecto; además de sus prácticas, modos de ser y otros elementos de su identidad cultural cuando entra en contacto con la sociedad o cultura dominante Por otro lado, es importante tener presente que proceso puede ser voluntario, basado en la suposición, no necesariamente correcta, de que así disfrutarán de las ventajas del grupo mayoritario (Martín y Riaño, 2016) 
territoriales y el mejoramiento de las atenciones de aquellos niños y niñas que requieren de apoyos de mayor complejidad.

Desde el punto de vista legal, es posible visualizar un conjunto de normativas, leyes y decretos que buscan asegurar una educación de calidad para los estudiantes que presentan NEE, ya sean de carácter permanente o transitorio. Entre las más recientes destacan ${ }^{6}$ :

- Decreto $1 / 98$ y decreto $1300 / 2002$, que aprueban planes y programas de estudio para alumnos con trastornos específicos del lenguaje.

- Ley 19.284/1994, que establece normas para la plena integración social de las personas con discapacidad.

- Decreto 201/2008, que ratifica la Convención Internacional sobre los Derechos de las Personas con discapacidad.

- Ley 20.201/2007, y su reglamento, decreto 170/2009, Orientaciones técnico-pedagógica para la evaluación integral.

- Artículo 34 del DFL No 2/2009, que mandata al Mineduc para establecer criterios y orientaciones de adecuación curricular.

- Ley 20.422/2010, de igualdad de oportunidades e inclusión social para las Personas con discapacidad, articulo 3 señala, entre sus principios, el Diseño Universal de Aprendizaje (DUA), decreto 83/2015 que incluye orientaciones para implementar adecuaciones curriculares para personas con necesidades educativas.

- Ley 20.845/2015, de Inclusión Escolar que regula la admisión de los estudiantes, elimina el financiamiento compartido y prohíbe el lucro en establecimientos educacionales que reciben aportes del Estado.

Más allá de los avances, en muchos aspectos pioneros en Latinoamérica, se verifica que la inclusión educativa en Chile ha estado focalizada fundamentalmente en la atención de estudiantes con $\mathrm{NEE}^{7}$; situación que es coincidente con lo que ocurre en otras latitudes (Artiles y Kozleski, 2014). La atención, inclusive, de estudiantes académicamente talentosos, que es otra forma de NEE, aún es incipiente, habiendo sido impulsada, básicamente, por la Universidad Católica de Chile, a través del Programa de Estudios y Desarrollo

\footnotetext{
6 Para un estudio pormenorizado de la normativa legal referida a la educación especial consultar: https://www.leychile.cl/Consulta/listado_n_sel?_grupo_aporte=\&sub=796\&agr=2\&comp=

7 Esta tendencia para el caso espańol Alba García-Barrera (2017) la llega a definir como un lastre, dado el carácter reduccionista con que se suele usar el concepto NEE.
} 
de Talentos Académicos (PENTA - UC) y de los programas que han replicado esta iniciativa en algunas universidades regionales.

La inclusión de estudiantes, objeto de discriminación o exclusión social de los sistemas educativos formales, motivados por su pertenencia a pueblos originarios, minorías étnicas, migrantes, disidentes sexuales o de género, entre muchos otros aspectos, no solo ha sido descuidada, sino que muy recientemente se ha tomado conciencia acerca de sus requerimientos y, consecuentemente, de la necesidad de contar con una normativa legal que atienda a sus especificidades; así como de la preparación que requieren los profesionales de la educación que diariamente conviven con ellos en la sala de clases (Valladares, 2013; Cornejo, 2019).

En otras palabras, los desafíos presente y futuro de la educación en Chile no se reducen apenas a la calidad de la educación que se imparte en las escuelas, concebida esta como una noción abstracta, descontextualizada o desvinculada de la multiplicidad de condicionantes que inciden en ella, sino que necesariamente supone atender a esas condicionantes en vista de optimizar los procesos de enseñanza-aprendizaje. En otras palabras, la inclusión educativa no es solo una exigencia de promoción y defensa de los derechos humanos de ciertos estudiantes, sino también una condición que posibilita una educación de calidad; pues no se cumple con la función básica de la escuela que es enseñar cuando ciertos estudiantes están limitados en sus posibilidades de aprender en razón de la discriminación o exclusión de la que son objeto.

\subsection{Inclusión educativa en perspectiva}

La exclusión se constituye en las sociedades contemporáneas como un elemento distintivo de las mismas que se verifica en diferentes niveles y esferas: política, social, económica, institucional, etc. De allí, la necesidad de diseñar políticas, estrategias y mecanismos que combatan la exclusión, el modo de desarrollar y poner en prácticas orientaciones y actividades inclusivas, especialmente en el ámbito educativo.

Del mismo modo que la exclusión, se torna en una realidad rutinaria presente en los más diversos ámbitos, la inclusión puede ser plasmada en cualquier sociedad, teniendo en consideración los diferentes contextos y situaciones. En este sentido, la inclusión no se restringe a ciertos grupos o a determinados ambientes. Dada la exigencia ética que deviene del reconocimiento y defensa de los derechos humanos, ella ha de hacerse presente en todas las esferas de la vida humana (Booth y Ainscow, 2002). 
Esta perspectiva implica considerar que inclusión y exclusión son procesos interligados que coexisten en una relación dialéctica, la cual genera subjetividades específicas que van desde el sentirse incluido al sentirse discriminado (Sawaia, 1999).

Con todo esto, tales subjetividades no acontecen en un continuum, pues no se explican solo por la determinación económica, sino determinan y son determinadas por formas diferenciadas de legitimación social e individual. Dicho, en otros términos, la exclusión es al mismo tiempo un proceso sutil y dialéctico, complejo y multifacetado, una configuración de dimensiones materiales, políticas, relacionales y subjetivas que envuelve a la persona por entero y sus relaciones con los otros, que no tiene una única forma o no es una falla del sistema, sino, por el contrario, es producto de su funcionamiento (Sawaia, 1999).

En consideración a esas características, la identificación y análisis de los procesos de exclusión e inclusión han de tener en cuenta tres dimensiones claves a la hora de intentar desenmarañar ese entramado de relaciones y superposiciones: las culturas, las políticas y las prácticas (Santos y Moreira, 2014; Santos, Santiago, Melo, 2018). Con relación a la primera, la creación de culturas inclusivas considera los aspectos educativos y de salud como elementos centrales con sus respectivas instituciones (Booth y Ainscow, 2002).

Dos aspectos fundamentales que deberían orientan a las instituciones educacionales caracterizadas por una cultura inclusiva están referidos a la construcción de una comunidad inclusiva y al establecimiento de valores inclusivos en esa comunidad. La construcción de una comunidad inclusiva debería hacer que esas comunidades se preguntasen si todos los estudiantes se sienten acogidos, si se ayudan unos a otros, si los profesores son capaces de conformar equipos de trabajo, entre otras preguntas (Cox, 2001; Casanova, 2011).

Además de esos elementos, se podrían citar dos aspectos que deberían orientar las investigaciones sobre inclusión en un establecimiento educacional: por una parte, el desarrollo de una institución para todos y, por otra, la organización de apoyo a la diversidad. Algunas medidas que podrían ayudar en este propósito son el apoyo que deberían recibir los profesores noveles en su adaptación al establecimiento y sus políticas inclusivas, y la conformación de grupos de estudiantes variados donde todos se sientan valorados (Devalle de Rendo y Vega, 2006)

Respecto de las prácticas inclusivas, se debería incentivar que las comunidades educativas reflexionen acerca de las culturas y políticas inclusivas del establecimiento, asegurando que todas las actividades de la sala de clases y/o extracurriculares efectivamente promuevan la participación de todos los 
estudiantes (Santos y Moreira, 2014; Santos, Santiago, Melo, 2018). Es decir, la enseñanza y el apoyo son considerados en el diseño de los aprendizajes y en la superación de las barreras de aprendizaje y participación. Asimismo, los profesores movilizan los recursos dentro del establecimiento y en las comunidades locales para incentivar un aprendizaje activo para todos los estudiantes (Booth y Ainscow, 2002).

En esta misma línea, dos aspectos contribuyen para que las instituciones educacionales investiguen acerca del grado de inclusión presente en sus prácticas. Por un lado, la forma como el aprendizaje es administrado y, por otra, la forma como la institución moviliza sus recursos en vistas de tornar posible la inclusión.

\section{Metodología}

El enfoque metodológico del estudio privilegia lo cuantitativo, con un diseńo descriptivo — correlacional- y consistió en la aplicación de una encuesta aplicada a 57 académicos $(90,4 \%)$ de un universo total de 63 directamente involucrados en la formación de profesores (56\% varones y $44 \%$ mujeres) adscritos a las Facultades de Educación, Ciencias y Ciencias Religiosas de la UCM, independientemente de su jerarquía académica o jornada laboral.

De esa muestra, se excluyeron los académicos del Departamento de Educación Especial, en razón de que estos profesionales tienen un conocimiento especializado del tema en estudio, y de aquellos que imparten asignaturas de formación general dependiente del Instituto de Estudios Generales no directamente relacionados con la formación de profesores.

Los académicos encuestados fueron consultados acerca de sus percepciones y actitudes en relación con la inclusión educativa, intentando averiguar, en primer término, cuál es su noción respecto del tema, las vinculaciones que establecen entre necesidades educativas especiales e inclusión educativa, el reconocimiento de otros grupos objeto de exclusión y/o discriminación en los sistemas escolares formales, los nudos críticos que supone la atención de algunos de estos grupos y las posibilidades de formación que ofrece la citada casa de estudios.

A los académicos que hicieron parte del estudio, se les aplicó una encuesta, especialmente diseñada para ese propósito, sobre la base de una escala Likert que constaba de treinta afirmaciones, subdividido en cinco dimensiones o ejes temáticos. Algunos de los resultados obtenidos son expuestos en este artículo, a través de figuras y sus respectivos comentarios, con el propósito de ilustrar las percepciones y actitudes de los entrevistados respecto del tema en estudio. 
Entre las consideraciones éticas del estudio, destaca el carácter «voluntario» de la participación de los encuestados, no mediando ninguna retribución económica, además de garantizárseles su anonimato. El material obtenido de las encuestas fue utilizado única y exclusivamente para los fines declarados en esta investigación.

\section{RESULTADOS Y DISCUSIÓN}

La selección de figuras y los comentarios, los cuales se presentan a continuación, ilustran algunas de las percepciones y actitudes de los académicos encuestados sobre la problemática y desafíos presentes en las discusiones en torno a la inclusión educativa en el contexto de la producción intelectual contemporánea y de los organismos internacionales. Las figuras fueron agrupadas de acuerdo a las temáticas comunes que ilustran las opiniones de los encuestados ante una afirmación sobre la cual fueron consultados.

\subsection{Ideas en torno a la inclusión educativa}

La primera figura hace referencia a una discusión recurrente en el contexto escolar chileno, motivada por la presencia de estudiantes con NEE en escuelas comunes. Básicamente, los cuestionamientos a los denominados "programas de integración escolar» devienen de la pregunta de si estos son efectivamente proyectos inclusivos, más allá de los recursos invertidos, los apoyos profesionales adicionales a la labor del profesor, la puesta en común de los espacios escolares, etc ${ }^{8}$. Esto es, si se puede hablar en propiedad de inclusión educativa en las escuelas nacionales o simplemente de esfuerzos de integración de estudiantes que tradicionalmente estuvieron marginados. Esfuerzo que lejos de promover una «inclusión auténtica» o "efectiva»" (Barrio de la Puente, 2009; Reiser, 2012; Ocampo, 2014), en algunos casos, puede devenir subalternización de esos mismos estudiantes (Galaz, 2012).

8 Un estudio reciente llevado a cabo por un grupo de investigadores (Tamayo, Carvallo, Sánchez y Rebolledo, 2018) muestra las brechas y desigual implementación de los programas de integración escolar, aún para los estudiantes con NEE.

9 De acuerdo a la propuesta de Rieser (2012), la educación inclusiva efectiva es aquella que se basa en el respeto de los derechos humanos y se inspira en modelos sociales innovadores. Entre las tareas de este tipo de educación está la identificar las barreras y encontrar soluciones. Estas soluciones deben ser actitudinales y culturales, ambientales y organizativas; además, deben operar a nivel nacional, regional y escolar, esto es, a nivel del aula. 
Respecto a los entrevistados, en su mayoría, se muestran en desacuerdo, pues la integración, aunque necesaria, aún dista mucho de una auténtica inclusión, especialmente por la forma en que se han llevado a cabo los programas de integración escolar en el país, en donde los profesores no han sido preparados para lidiar con estudiantes con distintos requerimientos de aprendizaje o simplemente con la heterogeneidad del estudiantado (Arroyo, 2008; Valladares, 2013; Santos y Moreira, 2014); o donde se ha privilegiado un acceso equitativo a los recursos económicos (Ley 20.845/2015, de Inclusión Escolar) con descuido de los soportes pedagógicos o la conformación de equipos de trabajo efectivamente multidisciplinarios.

\section{Figura 1. La inclusión educativa es una forma de integración en los sistemas educativos formales}

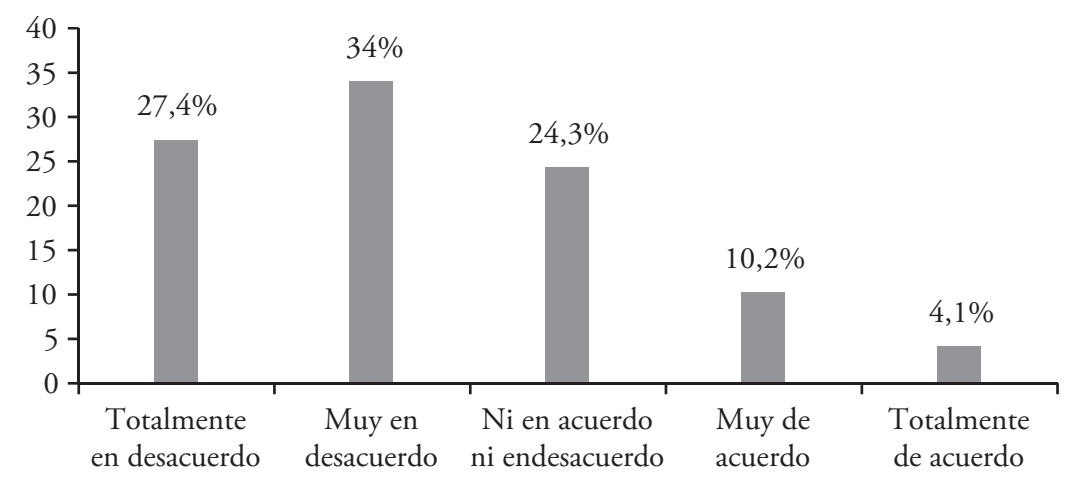

Fuente: Resultados de la encuesta aplicada a los académicos responsables de la formación de profesores de la UCM.

En la segunda figura, los entrevistados, en su mayoría, se muestran en desacuerdo en que la inclusión educativa sea inviable en sectores rurales. La tentación de creer que la falta de recursos es una excusa para no desarrollar programas inclusivos, claramente, les resulta poco convincente, pues, sobre los recursos, las posibilidades de éxito de los programas de inclusión pasan por una cuestión de voluntad (Tamayo, Carvallo, Sánchez y Rebolledo, 2018). En esta misma línea, una columna periodística, con motivo del día internacional de la educación, daba cuenta de las brechas entre la educación rural y la urbana en materia de inclusión y calidad. "Para que la juventud rural pueda desplegar su potencial y contar con oportunidades equivalentes a las de sus pares urbanos, se requiere profundizar los esfuerzos de inclusión y calidad que beneficien al sistema educativo en su conjunto» (Fernández, s.f.). 


\section{Figura 2. La inclusión educativa es inviable en sectores rurales o socialmente vulnerables}

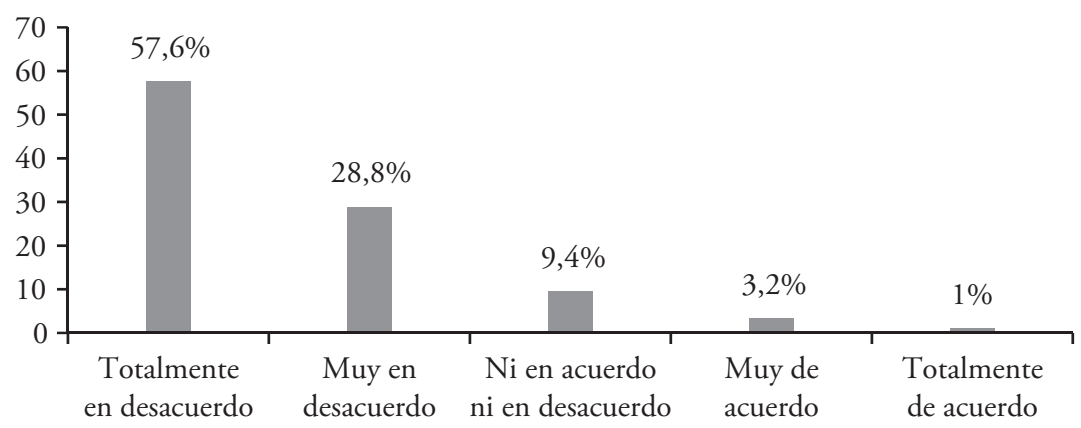

Fuente: Resultados de la encuesta aplicada a los académicos responsables de la formación de profesores de la UCM.

En la tercera figura, los entrevistados fueron consultados sobre los procesos de homogeneización, asimilación y normalización ${ }^{10}$, prácticas frecuentes en el sistema educativo nacional, intentando saber si para ellos estas son formas de inclusión educativa. Como se puede observar los académicos encuestados, en su mayoría, se muestran contrarios a esos intentos, argumentando que tradicionalmente el sistema educacional chileno ha tendido a invisibilizar o silenciar las diferencias.

${ }^{10}$ N. Bank-Mikkelsen lanzó un nuevo principio al que se denominó normalización y que formuló como: «La posibilidad de que los deficientes mentales lleven una existencia tan próxima a lo normal como sea posible». Este postulado quedó reflejado más tarde en la normativa danesa (1959). Diez años más tarde, en 1969, B. Nirje, trabajó sobre este término, profundizándolo y reformulándolo como: "Hacer accesibles a los deficientes mentales las pautas y condiciones de la vida cotidiana que sean tan próximos como sea posible a las normas y pautas del cuerpo principal de la sociedad». Desde los países escandinavos, este principio se fue extendiendo por toda Europa y alcanzó los Estados Unidos y Canadá, donde W. Wolfensberger volvió a modificar la definición de este principio de normalización dándole un timbre más didáctico: «Normalización es la utilización de medios culturalmente normativos (familiares, técnicas valoradas, instrumentos, métodos, etc.), para permitir que las condiciones de vida de una persona (ingresos, vivienda, servicios de salud, etc.) sean al menos tan buenas como las de un ciudadano medio, y mejorar o apoyar en la mayor medida posible su conducta (habilidades, competencias, etc.), apariencia (vestido, aseo, etc.), experiencias (adaptación, sentimientos, etc.), estatus y reputación (etiquetas, actitudes, etc.)». El principio de normalización fue evolucionando de manera que se puede identificar a través de las siguientes afirmaciones: a) De una aplicación exclusiva a las personas con retraso mental se amplía a cualquier persona; b) No solo se trata de un resultado (BankMikkelsen), o de poner especial énfasis en los medios (Nirje), sino que se tiene que considerar de forma conjunta los medios y los resultados (siguiendo a Wolfensberger); c) No es únicamente un conjunto de actuaciones (aplicables solo o principalmente al sistema educativo) sino unos principios dirigidos a todo el sistema, tanto al sujeto con discapacidad como a la sociedad en que vive (Rubio, 2009). 
Figura 3. Los procesos homogeneizadores, asimilacionistas y normalizadores son formas de inclusión educativa.

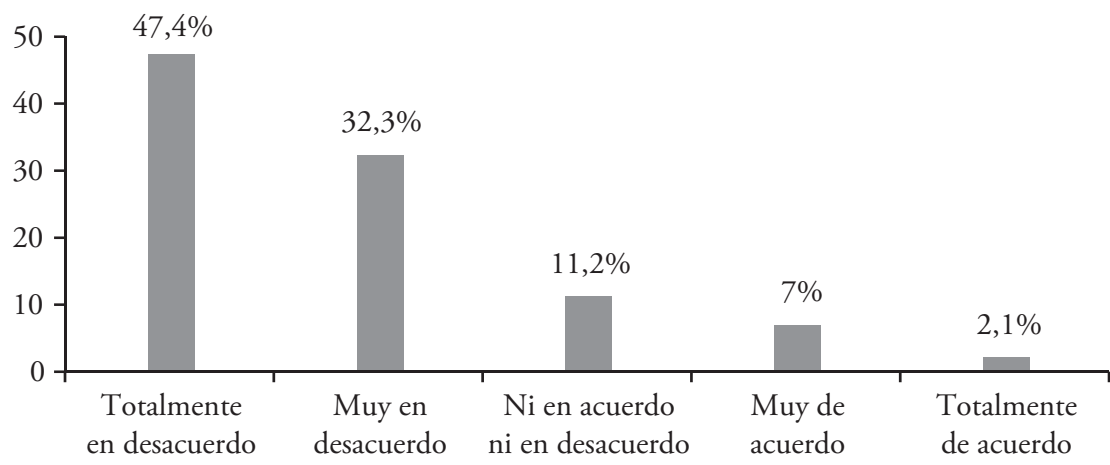

Fuente: Resultados de la encuesta aplicada a los académicos responsables de la formación de profesores de la UCM.

\subsection{Inclusión educativa y NEE}

En la figura 4, se aprecia que los entrevistados se muestran contrarios a la idea que tendió a predominar hasta la década de 1990, donde se creía que la inclusión educativa tenía poco que ver con las otras formas de exclusión y/o discriminación presentes en los sistemas escolares formales; ya sea porque dichas exclusiones estaban naturalizadas por las prácticas sociales o porque había menos conciencia que la escuela puede ser un espacio generador de exclusiones de diferente orden (Unicef, 2012; Artiles y Kozleski, 2014).

Figura 4. La inclusión educativa se preocupa solo de los estudiantes con NEE.

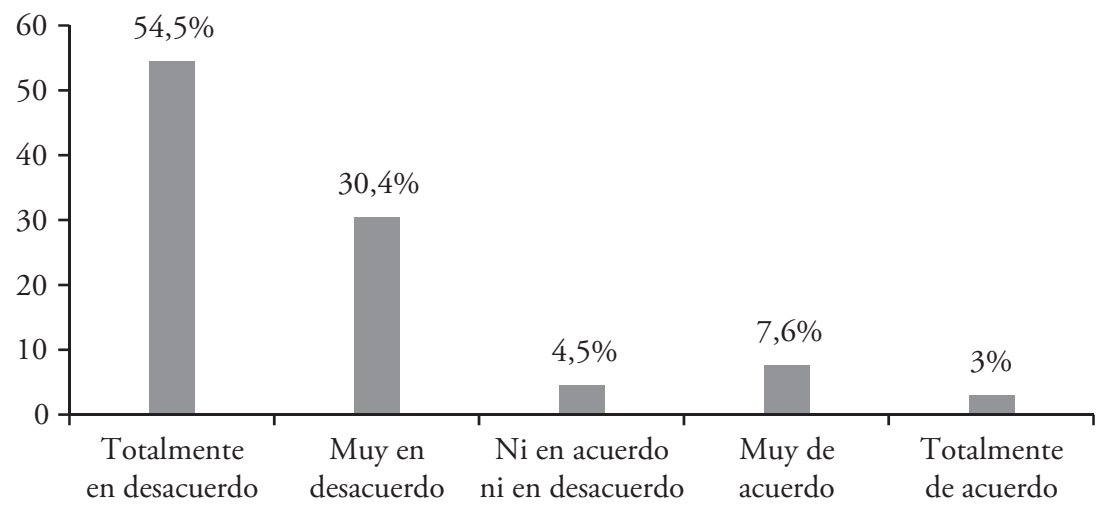

Fuente: Resultados de la encuesta aplicada a los académicos responsables de la formación de profesores de la UCM. 
En la figura 5, se aprecia que la gran mayoría de los entrevistados tienen una noción amplia de NEE que contempla no solo la atención de los estudiantes descendidos, sino también a los académicamente talentosos que son una forma inversa en la concepción de las NEE.

Figura 5. Las NEE deberían consideran no solo a los estudiantes descendidos sino también a los estudiantes talentosos

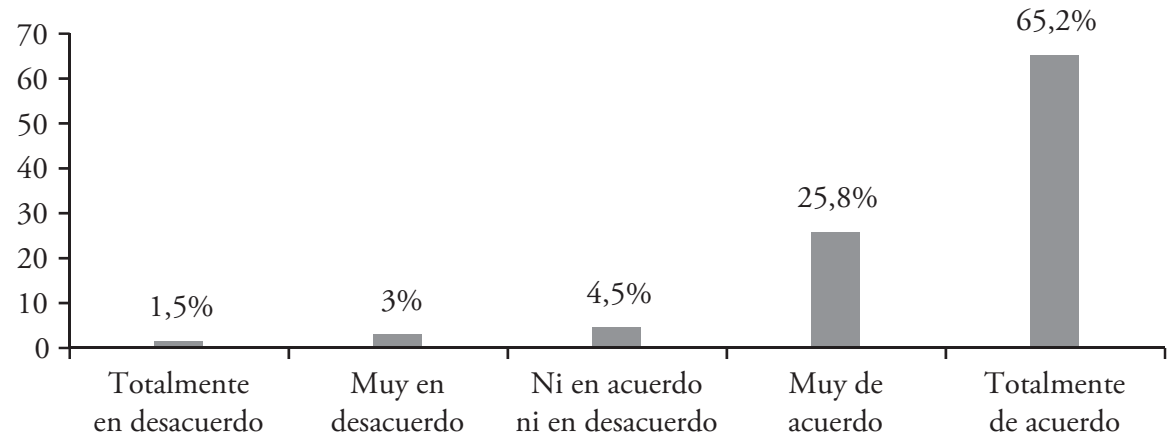

Fuente: Resultados de la encuesta aplicada a los académicos responsables de la formación de profesores de la UCM.

Figura 6. La presencia de un estudiante con NEE o con capacidades distintas retrasa el avance de sus compañeros

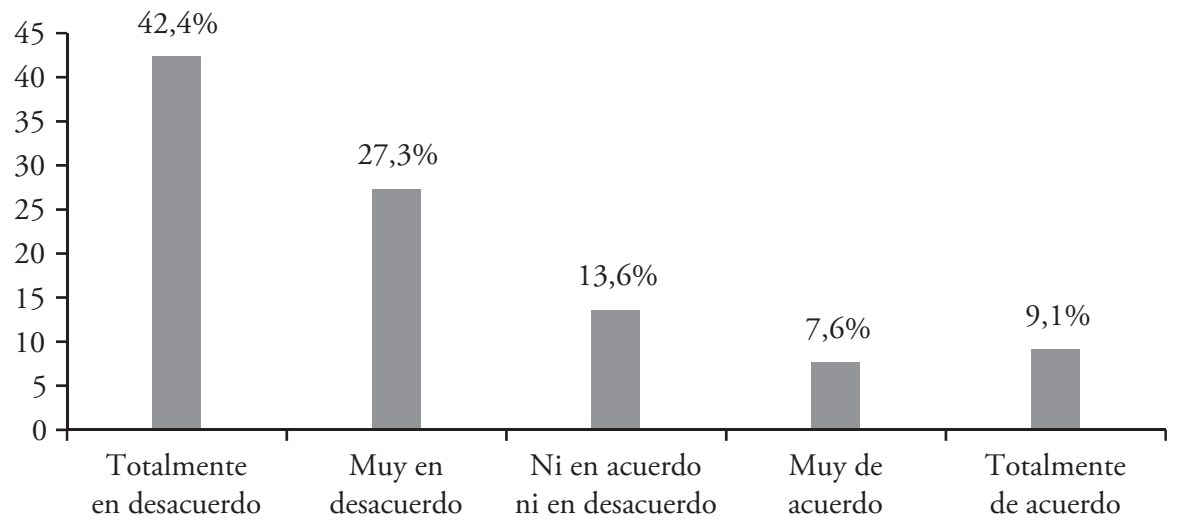

Fuente: Resultados de la encuesta aplicada a los académicos responsables de la formación de profesores de la UCM. 
En la figura 6, se infiere que son mayoritarias las opiniones que sostienen que la presencia de estudiantes con NEE no afecta los aprendizajes de los otros estudiantes, pero llama la atención, si se compara esta gráfica con las dos anteriores, que las opiniones se van matizando y tornándose menos categóricas. La razón de ello, probablemente, está en las limitaciones en términos de infraestructura y recursos que, en general, evidencian los establecimientos educacionales y a la falta de preparación del profesorado para atender a comunidades escolares heterogéneas (Sanhueza, Granada y Bravo, 2012; Unicef, 2012, Dos Santos y Moreira, 2014, Rojas y Armijo, 2016).

\subsection{Reconocimiento de otros grupos objeto de exclusión y/o discriminación}

La figura 7 hace alusión a un debate abierto en Chile sobre cuáles son los alcances de los procesos globalizadores y la inmediatez de la información facilitada por la masificación de internet y de los medios de comunicación social, que de algún modo han contribuido a diluir o tornar más flexibles las identidades nacionales, o lo que tradicionalmente se entendía por ello. En el entorno de una cultura global que tiende a la homogeneización, han surgido voces disidentes que se resisten a los intentos asimilacionistas. Tal proceso se torna más complejo en países como Chile, pues, las presiones no solo provienen de la cultura global, sino también, en el ámbito interno de los pueblos originarios que reivindican una identidad propia, históricamente negada o invisibilizada por la cultura y el sistema educacional, que en vista de la construcción de una identidad nacional única y homogénea sistemáticamente obvia cualquier disonancia. Respecto a esto, los encuestados parecieran reproducir las mismas diferencias presentes en el debate público. Si bien un $22,7 \%$ se muestra en completo desacuerdo con las políticas asimilacionistas, el 28,8\% se muestra en total acuerdo. En otras palabras, el tránsito entre una ciudadanía global que permita adoptar los códigos de la modernidad y una latinoamericanidad inclusiva entendida como la suma de esencias nacionales, como postula E. Samper (2002), pareciera ser aún un tema no resuelto ni menos aún internalizado, especialmente en momentos en que a las reivindicaciones indígenas se suma el desconcierto que provoca la presencia cada vez más visible de estudiantes migrantes en las escuelas del país. 
Figura 7. Los estudiantes pertenecientes a grupos étnicos minoritarios o a pueblos originarios deberían ser asimilados a la cultura nacional.

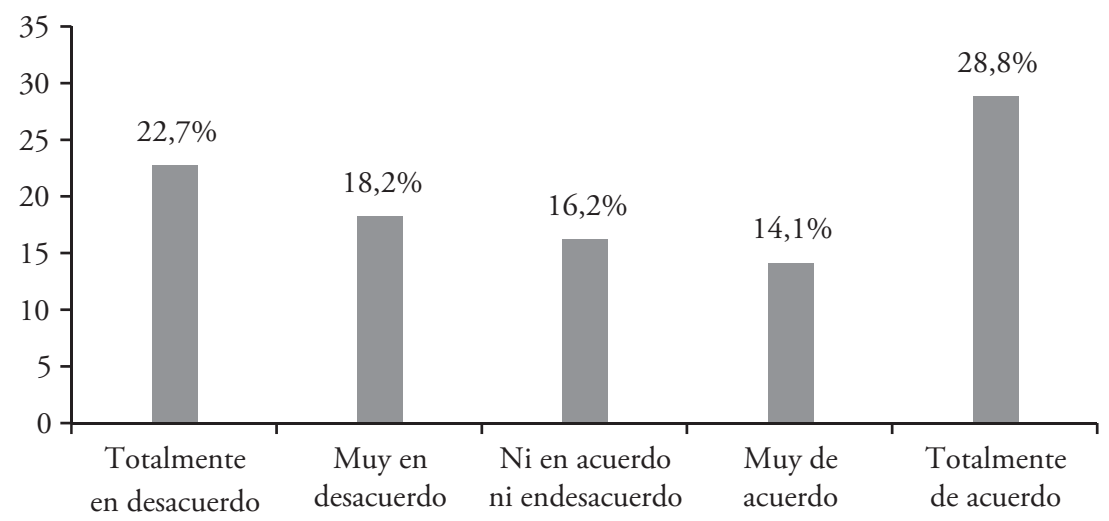

Fuente: Resultados de la encuesta aplicada a los académicos responsables de la formación de profesores de la UCM.

Frente a la consulta de si una sociedad sexista, patriarcal y xenofóbica favorece la exclusión de los estudiantes pertenecientes a grupos minoritarios o disidentes del orden establecido, los encuestados se manifestaron mayoritariamente de acuerdo (ver figura 8). A este respecto, cabe recordar que numerosos estudios llevados a cabo en la presente década muestran que, pese a la mayor conciencia, en Chile aún prevalecen prácticas excluyentes, las cuales hacen que ciertos grupos se sientan discriminados. A modo de ejemplo, se puede citar la Séptima Encuesta Nacional de Juventud (2013) del Instituto Nacional de la Juventud (INJUV) que afirmaba que uno de cada tres jóvenes decía sentirse discriminados. Entre los grupos más expuestos a la discriminación, estaban los gitanos, las personas con discapacidad mental y los homosexuales.

La figura 9 ilustra el parecer de los encuestados que fueron consultados sí los estudiantes LGBT (Lesbiana, Gays, Bisexuales, Transgénero y Transexuales) se encuadraban dentro de los grupos objeto de preocupación de la inclusión educativa, se manifestaron en su gran mayoría de acuerdo; es decir, a juicio de estos académicos, las disidencias sexuales poco tienen que ver con la inclusión educativa.

No deja de llamar la atención este parecer, si comparado con las expresiones contenidas en la figura 8, donde, claramente, coincidían en que el sexismo, y la xenofobia son causales de discriminación. Todavía más, al cruzar esta información con otro estudio cualitativo basado en entrevistas en profundidad a un 
grupo de esos mismos académicos acerca del mismo tópico, las conclusiones parecieran ser coincidentes (Cornejo, 2016).

Figura 8. Una sociedad sexista, patriarcal, xenofóbica... favorece la exclusión de los estudiantes pertenecientes a grupos minoritarios o disidentes del orden establecido.

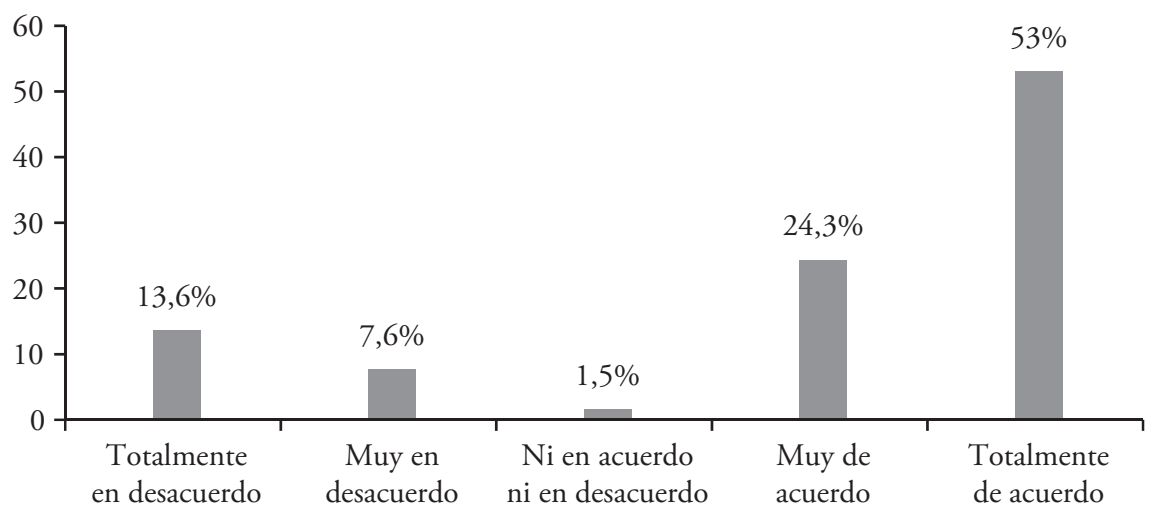

Fuente: Resultados de la encuesta aplicada a los académicos responsables de la formación de profesores de la UCM.

Figura 9. Los estudiantes LGBT (Lesbiana, Gays, Bisexuales, Transgénero y Transexuales) no se encuadran dentro de los grupos objeto de preocupación de la inclusión educativa

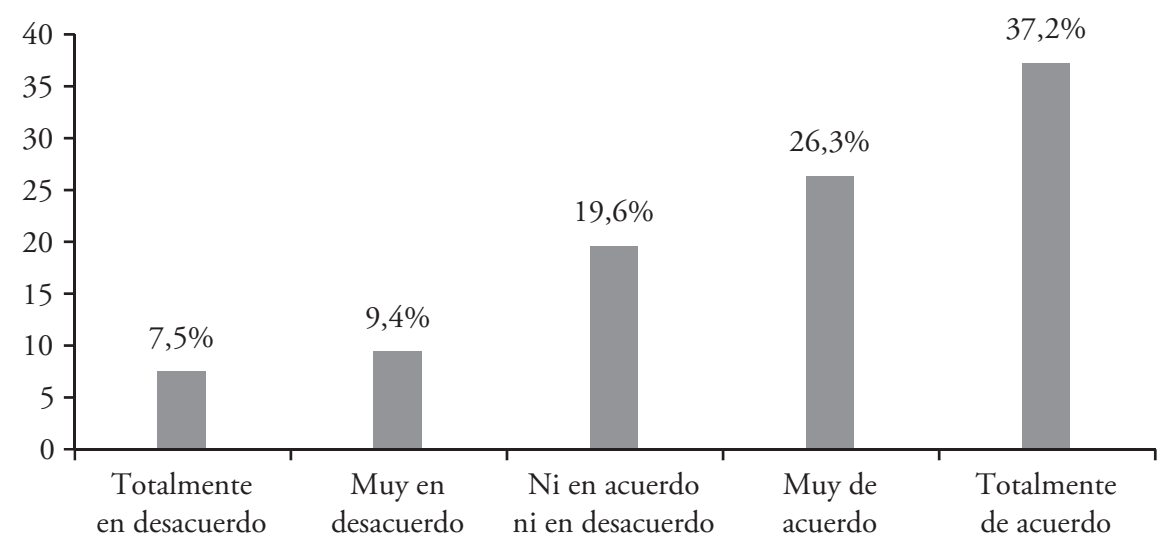

Fuente: Resultados de la encuesta aplicada a los académicos responsables de la formación de profesores de la UCM. 
Los estudiantes LGBT no solo son los más expuestos al bullying (homofóbico) en Chile (y en otras latitudes) como sostiene el estudio de Unesco (2012), sino que la sola alusión al tema aún es ampliamente resistida en ámbitos académicos y escolares, probablemente, motivada por convicciones religiosas, filosóficas o ideológicas de los distintos agentes educativos, que de alguna forma tienden a legitimar la discriminación e invisibilización de que son objeto estos estudiantes en los sistemas escolares formales. No obstante, no se puede obviar el hecho de que no solo no se vulneran los derechos cuando se infringe daño directamente, sino también cuando se invisibiliza o se impone una ley del silencio (Fernándes Dinis, 2011).

\subsection{Nudos críticos de la inclusión educativa}

La figura 10 alude a una práctica frecuente en el sistema educacional chileno que tiene relación con la aplicación de pruebas de selección para el ingreso a determinados establecimientos. Práctica que se ha intentado erradicar a través de la Ley de Inclusión Escolar (2015), la cual establece que ningún establecimiento que reciba algún tipo de subvención de parte del Estado puede aplicar este tipo de pruebas ${ }^{11}$.

La anterior ha incidido en que, principalmente, los establecimientos administrados por los municipios y algunos particulares subvencionados sean los que concentren el mayor número de estudiantes con problemas de aprendizaje, conductuales o de convivencia escolar; así como a estudiantes de menores ingresos o pertenecientes a grupos marginalizados. Situación que, indudablemente, ha incidido en la configuración de un sistema educacional fuertemente segmentado y que, en gran parte, se origina por la aplicación de pruebas de selección que no hacen sino perpetuar el régimen de exclusión vigente (Blanco, 2011; Rojas y Armijo, 2016).

\footnotetext{
11 La posibilidad de que los establecimientos educacionales apliquen pruebas de selección a sus estudiantes es un tema controvertido a nivel nacional e internacional. La mayoría de los países aplican restricciones y prohibiciones a los procesos de selección a partir de variables sociales, económicas o étnicas, pero no así en términos académicos o valóricos. En Chile, la Ley General de Educación (LGE) prohíbe expresamente la discriminación por motivos económicos, raciales o étnicos en todos los niveles, instaurando algunos preceptos generales desde la perspectiva del derecho a la educación, como a la no discriminación, la accesibilidad, la ecuanimidad en la provisión, entre otros. Sin embargo, la misma ley faculta a los establecimientos la potestad de seleccionar por criterios académicos desde Séptimo Básico, un par de años antes que la mayoría de los países de la OCDE (Organización para la Cooperación y el Desarrollo Económicos). Asimismo, la interpretación de esa misma ley genera una alta ambigüedad respecto de las posibilidades de los establecimientos de seleccionar respecto de las características valóricas de los padres, niños y niñas y su alineación con el proyecto educativo de los establecimientos, anteponiendo con ello el derecho de construcción de un proyecto educativo por sobre el interés superior del niño o niña (Villalobos, 2014).
} 
Figura 10. Las pruebas de selección de estudiantes que aplican algunos establecimientos educacionales del país no favorecen la inclusión educativa

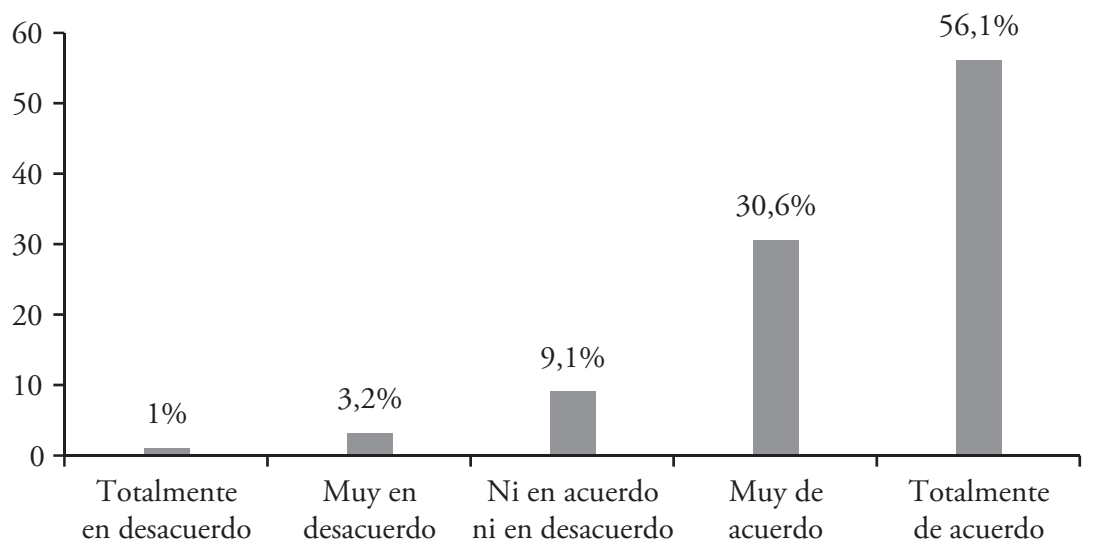

Fuente: Resultados de la encuesta aplicada a los académicos responsables de la formación de profesores de la UCM.

Figura 11. Un currículo o plan de estudio rígido no favorece la inclusión educativa

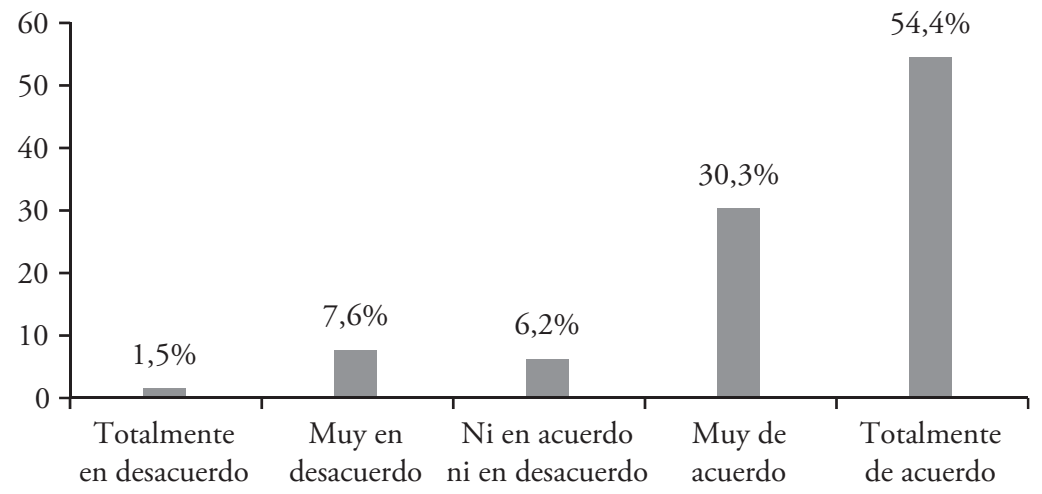

Fuente: Resultados de la encuesta aplicada a los académicos responsables de la formación de profesores de la UCM.

Consultados los entrevistados acerca de los efectos negativos que inviabilizan las posibilidades de inclusión educativa, en su gran mayoría se manifiestan total o muy acuerdo; esto es, coinciden en la apreciación negativa respecto de este tipo de pruebas.

Una situación similar ocurre cuando se les consulta acerca de las dificultades que ocasiona un currículo rígido, es decir, que ofrece pocas posibilidades 
de adaptación o innovación pedagógica de modo de atender a las distintas realidades educacionales o a los distintos grupos presentes en los sistemas escolares. Al igual que en la gráfica anterior, los entrevistados se manifiestan masivamente de acuerdo en que un currículo rígido es un obstáculo en la puesta en marcha de proyectos inclusivos (Rieser, 2012; McManis, 2017; Manghi, Saavedra y Bascuñán, 2018).

Con todo, no se puede obviar que la inclusión no es tarea solo de la escuela o de los centros de formación de profesores sino un desafío que compromete a todo el espectro social. En este sentido, la educación inclusiva no se desentiende de la familia, de los medios de comunicación social, del mundo laboral ni de la opinión pública ni de cualquier otro elemento que pueda apoyar o limitar la calidad de vida de estas personas. La educación inclusiva no se podrá desarrollar en los centros educativos eficazmente si no se lucha contra la exclusión que existe dentro y fuera de ella, como sostiene Slee (2012).

En estrecha conexión con lo anterior, en la figura 12, los entrevistados coinciden, mayoritariamente, que la existencia de establecimientos sectorizados de acuerdo al nivel socio-económico es otro de los puntos clave que explican la existencia de un sistema altamente segmentado y gettizado; es decir, un sistema educacional que reproduce fielmente las diferencias sociales, con pocas o nulas posibilidades de integración social y, consecuentemente, con pocas oportunidades para una educación efectivamente inclusiva. Este diagnóstico ha sido confirmado en distintos estudios y en distintos momentos en las últimas dos décadas (García Huidobro, 2007; Blanco, 2011; Unicef, 2012).

Figura 12. La existencia de establecimientos educacionales sectorizados por nivel socio - económico no favorece la inclusión educativa.

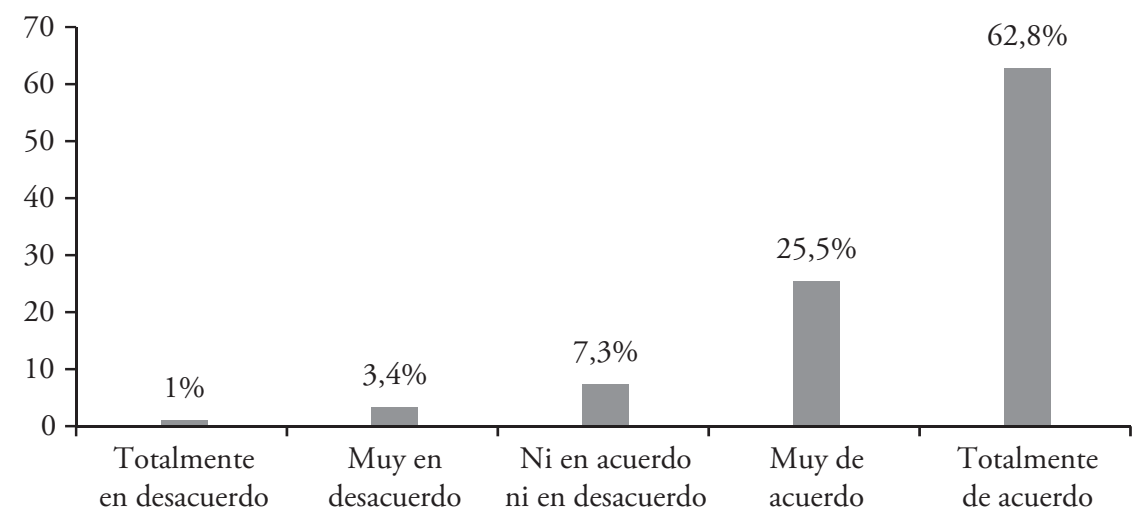

Fuente: Resultados de la encuesta aplicada a los académicos responsables de la formación de profesores de la UCM. 


\subsection{Posibilidades de formación en inclusión educativa que ofrece la UCM}

La figura 13 muestra que la gran mayoría de los académicos encuestados, pese a ser ellos mismos los responsables de la formación profesional, cree que los futuros profesores de la UCM no cuentan con las competencias necesarias para identificar a los estudiantes con NEE. Ello es explicable, porque en la malla de formación de esa Universidad no hay ningún curso que le permita a los estudiantes desarrollar esa habilidad, ni tampoco la temática es abordada a modo de contenido en otra asignatura.

Figura 13. Los futuros profesores de la UCM tienen las competencias necesarias para detectar a los estudiantes con NEE

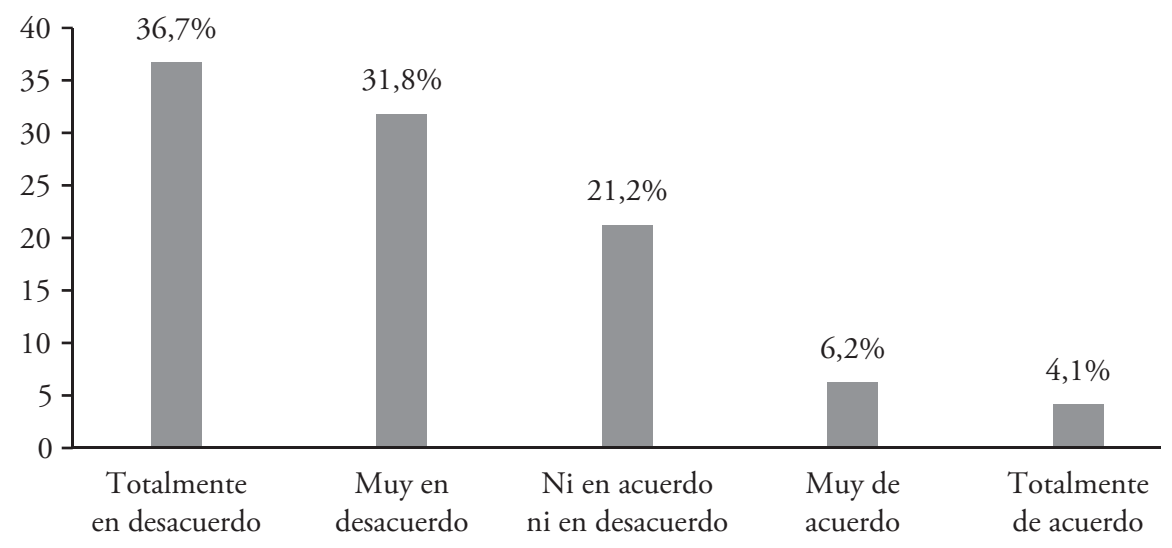

Fuente: Resultados de la encuesta aplicada a los académicos responsables de la formación de profesores de la UCM.

La información anterior coincide con lo que se desprende de la figura 14, donde los entrevistados son consultados sobre si los futuros profesores reciben la preparación necesaria para trabajar con comunidades escolares heterogéneas o resolver problemas de convivencia escolar derivados de esa misma diversidad y manifiestan, en su gran mayoría, que no cuentan con la preparación suficiente. Probablemente, esta deficiencia, como ocurre en la mayor parte de las universidades del país, es una de las mayores falencias que evidencia la formación de profesores de la UCM (Rojas y Armijo, 2016).

Dicho, en otros términos, se privilegia una formación que favorece la generalización y que no permite a los profesionales de la educación reconocer y valorar las diferencias (Arroyo, 2008; Blanco 2011). Es decir, la diferencia no es percibida como una oportunidad para el aprendizaje, sino que es vista como 
un obstáculo (Dos Santos y Moreira, 2014), motivo por el cual se invisibiliza y se silencia convirtiéndose en prácticas naturalizadas por el ejercicio pedagógico y por la gestión escolar.

En síntesis, lo descrito pareciera no ser solo un problema de las universidades formadoras de profesores (Slee, 2012). Es usual que los propios agentes educativos en ejercicio ante situaciones de conflicto o tensión al interior de los establecimientos o cuando la escuela se ve cuestionada socialmente, esgriman a modo de explicación o excusa la falta de preparación de los profesores para atender a comunidades heterogéneas y vulnerables (Tenorio, 2009; 2011, Rieser, 2012; McManis, 2017; Manghi, Saavedra y Bascuñán, 2018)). Situación que se ve agravada por los problemas de infraestructura, los bajos salarios y las condiciones poco gratificantes para el desarrollo profesional.

Figura 14. Los futuros profesores de la UCM reciben la preparación necesaria para trabajar con comunidades escolares heterogéneas y resolver problemas de convivencia derivados de esa misma diversidad

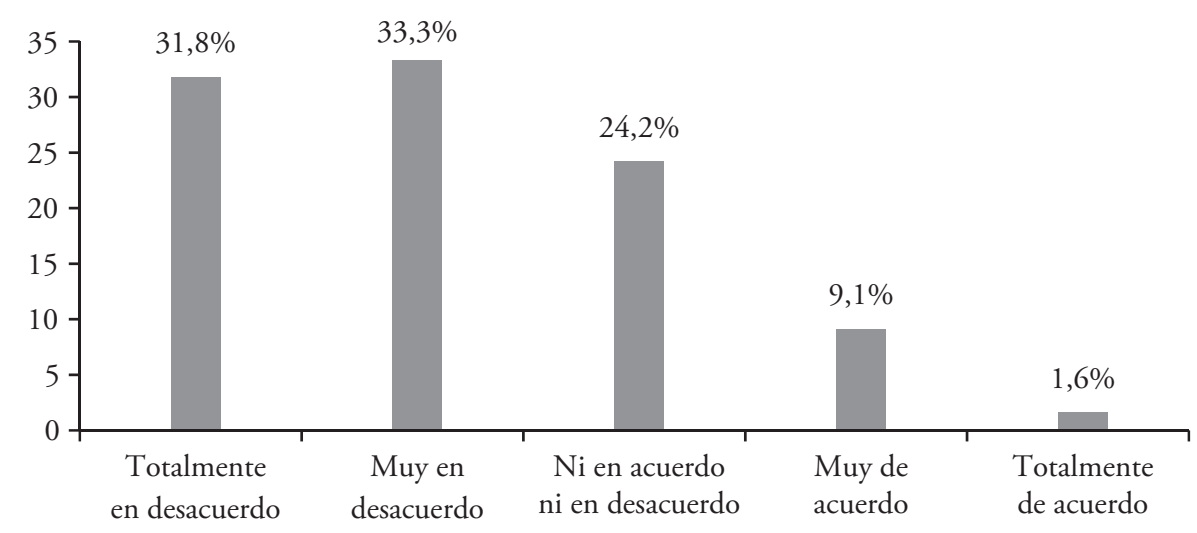

Fuente: Resultados de la encuesta aplicada a los académicos responsables de la formación de profesores de la UCM.

Finalmente, la figura 15 ilustra la opinión de los entrevistados con respecto a los requerimientos y desafíos que supone para los propios académicos la inclusión educativa. De lo que se desprende de sus respuestas, en su gran mayoría, cree que ellos mismos tampoco tienen los conocimientos necesarios o estos son insuficientes para trasmitirlos a sus estudiantes. Esta carencia explicaría los déficits en la materia que evidenciarían los futuros profesores de la UCM y la ausencia de la temática en el currículo de formación profesional. 
Figura 15. Los académicos responsables de la formación de profesores de la UCM conocen los requerimientos y desafíos que supone la inclusión educativa.

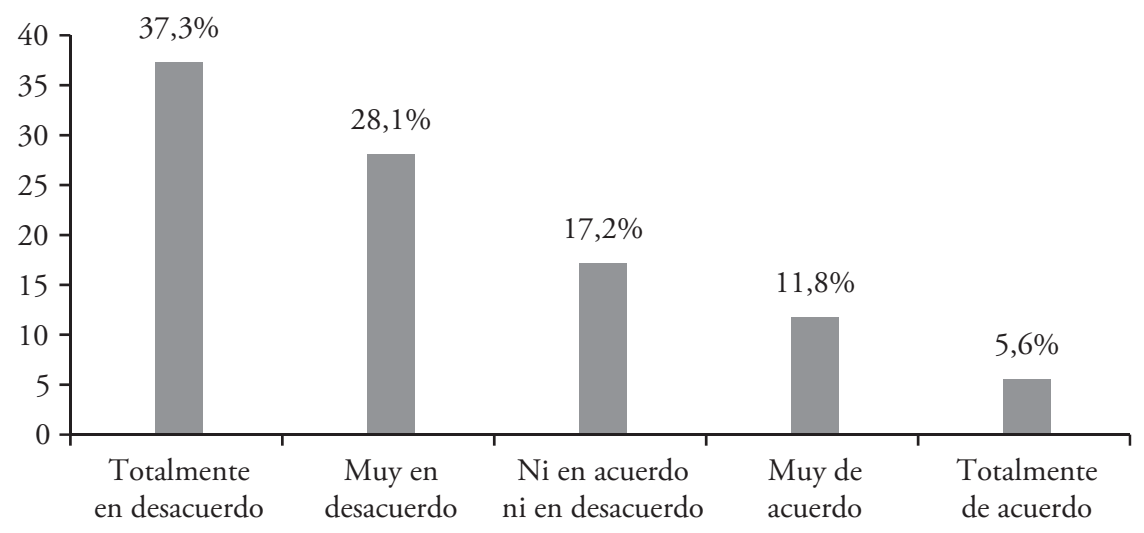

Fuente: Resultados de la encuesta aplicada a los académicos responsables de la formación de profesores de la UCM.

No obstante, no se puede obviar lo nuevo que resulta el tema, aún para los formadores de formadores, cuestión que implica un doble desafío: introducir tanto a los futuros profesores como a los académicos en la temática, de modo de transformar no solo la cultura escolar, sino la propia cultura universitaria (Ocampo, 2014).

\section{ConClusiones}

A modo de conclusión, se puede afirmar que, si bien las ideas de inclusión educativa se han ampliado progresivamente, no limitándose a las NEE, aún prevalecen ciertas nociones o matices en los dichos de los entrevistados que remiten a ideas de integración, asimilación u, homogeneización especialmente cuando se habla de pueblos originarios, minorías étnicas o migrantes homogeneización (Narodowski, 1999; Rubio, 2009; Martín y Riaño, 2016). Así, la inclusión, a juicio de algunos, necesariamente pasa por la asimilación a la cultura nacional, la cual a su vez es tributaria de los procesos globalizadores.

Donde sí todos parecen coincidir es en la falta de recursos, que la distancia de los centros urbanos no puede ser excusa para no implementar proyectos inclusivos, así como afirmar que la presencia de estudiantes con NEE sea un obstáculo para el aprendizaje de los otros estudiantes. 
Esta apreciación es coincidente con las exigencias y desafíos que pesan sobre los sistemas educativos contemporáneos, en el sentido de que la escuela debe ser un espacio abierto a la diversidad e inclusión sin excepciones, por cuanto ella debe facilitar el acceso de todos los estudiantes, incrementar la aceptación y participación en los distintos ámbitos de la vida escolar, además de mejorar los rendimientos (Barrio de la Puente, 2009).

Una perspectiva de educación inclusiva (...) que asume la inclusión como el derecho al recibo visceral de todos los sujetos educables al margen de su naturaleza, sin reducirlo a personas discapacitadas o de índole determinada, especial, es una manera de resignificar en la praxis pedagógica los presupuestos fundacionales del acto de educar, cada vez menos visible en este mundo que privilegia la rentabilidad económica en el marco de las relaciones humanas. La función de educar entraña la generación de espacios para formar mejores seres humanos; tal aspiración sitúa el acogimiento radical del otro como basamento de la relación educativa (Arboleda, 2019, p. 19).

Este supuesto se fundamenta, además, en la idea de que las comunidades escolares son básicamente "comunidades de diferencias». Entonces las diferencias no deben ser invisibilizadas, sino valoradas y puestas al servicio de los procesos de aprendizaje, porque la educación inclusiva exige un compromiso mayor de lo que a simple vista puede parecer. Su planteamiento si bien es sencillo, el derecho a la educación que tiene toda persona más allá de sus limitaciones, se complejiza, porque su desarrollo plantea numerosas interrogantes que cuestionan nuestras experiencias y saberes, tan anclados en un modelo educativo excluyente. La cultura de la que hacemos parte, la formación recibida, las políticas educativas vigentes, entre muchos factores, invisibilizan la segregación de las personas con menos recursos, incluso dentro de los establecimientos educacionales considerados inclusivos (Slee, 2012).

En el esfuerzo por configurar una noción ampliada de inclusión educativa, el pensar en otros grupos, más allá de los estudiantes con problemas de aprendizaje, pareciera no representar un problema. Es más, el sexismo, la xenofobia o el machismo les parecen, en opinión de la mayoría, sustratos ideológicos que legitiman y perpetúan la discriminación y exclusión social de ciertos grupos. Con todo, no deja de llamar la atención que al consultárseles por la inclusión de los estudiantes LGBT disidentes sexuales del ideario heteronormativo las opiniones no solo son menos categóricas, sino que se evidencian atisbos de la homofobia cultural presente en la sociedad chilena que impiden pensar en estos estudiantes como sujetos de políticas inclusivas. 
Respecto de los nudos críticos, claramente, los entrevistados visualizan en las pruebas de selección, un currículo rígido y la segmentación social un serio obstáculo para la inclusión educativa en el país. Obstáculo que en ciertos aspectos tornarían inviables proyectos que apunten no apenas a acciones reactivas remediales, sino a la construcción de una auténtica cultura educacional inclusiva (Blanco, 2011; Rojas, T. y Armijo, 2016).

Por último, con relación a las posibilidades de formación en inclusión educativa que ofrece la UCM, los propios entrevistados reconocen que los estudiantes que se están formando para profesores no tienen las competencias para implementar proyectos inclusivos efectivos, dado que la Universidad no los prepara para ello. Esta carencia evidencia, además, el desconocimiento o falta de preparación en la materia que tendrían los mismos formadores de formadores (Infante, 2010; Santos, Santiago, Melo, 2018). En otras palabras, si bien se ha tomado conciencia acerca de la necesidad de formar a los futuros profesores en inclusión educativa, en la UCM aún no existen proyectos curriculares concretos, quedando la idea de la inclusión más bien en el plano discursivo.

\section{REFERENCIAS BIBLIOGRÁFICAS}

Ainscow, M., Booth, T. y Dyson, A. (2006). Improving schools, developing inclusion. Londres: Routledge. https://doi.org/10.4324/9780203967157

Ainscow, M. (2009). Torna a educação inclusiva: como essa tarefa deve ser conceituada? En O. Fávero, W. Ferreira, T. Ireland y D. Barreiros (orgs.), Tornar a educação inclusive (pp. 11-24). Brasilia: Unesco - ANPED.

Aguerrondo, I. (2008). Revisar el modelo: Un desafío para lograr la inclusión. Perspectiva, 28(1), 61-80.

Arboleda, J. C. (2019). Pasivos y desafíos en la educación. Para una inclusión comprensiva edificadora. Revista boletín REDIPE, 8(4), 17-37.

Artiles, A. y Kozleski, E. (2014). Educación inclusiva en el siglo XXI: notas para un programa de investigación histórico-cultural. En M. C. Cardona y E. Chiner (eds.), Investigación educativa en escenarios diversos, plurales y globales (pp. 51-65). Alicante: AIDIPE - Universidad de Alicante.

Arroyo, M. (2008). Os coletivos diversos repolitizam a educação. En J. Diniz y G. Leâo (Organizadores). Quando a diversidade interroga a formaçâo docente (pp. 11-36) Belo Horizonte: Autêntica.

BibliotecadelCongreso NacionaldeChile(2009).LeyGeneraldeEducación20.370. Recuperado de https://www.leychile.cl/Navegar?idNorma=1006043

Barrio de la Puente, J. L. (2009). Hacia una educación inclusiva para todos. Revista Complutense de Educación, 20(1), 13-31. 
Blanco, R. (2011). Educación inclusiva en América Latina y el Caribe. Revista Participación Educativa, (18), 44-59. España: Ministerio de Educación, Cultura y Deporte.

Booth, T. y Ainscow, M. (2002). Index for Inclusión - developing learning and participation in schools. Bristol: CSIE.

Casanova, M. A. (2011). Educación inclusiva: un modelo de futuro. España: Wolters Kluwer.

Cornejo, J. (2012a). Educación, interculturalidad y ciudadanía. Educar em Revista, (43), 239-254. https://doi.org/10.1590/S0104-40602012000100016

Cornejo, J. (2012b). Retos impuestos por la globalización a los sistemas educativos latinoamericanos. Revista Mexicana de Investigación Educativa, 17(52), 15-37.

Cornejo, J. (2016). Tarefas pendentes em matéria de inclusão educativa: percepção dos acadêmicos da Universidade Católica do Maule - Chile. Educação em Questão, 54(41), 33-60. https://doi.org/10.21680/1981-1802.2016v5 4 n41ID10157

Cornejo, J. (2019). Nuevos excluidos en el sistema educacional chileno: problemas y desafíos. Revista Páginas de Educación, 12(1), 28-48. https://doi.org/ $10.22235 /$ pe.v12i1.1766

Cox, C. (2001). El currículum escolar del futuro. Perspectivas, 4(2), 213 -232. Recuperado de http://www.dii.uchile.cl/ $\sim$ revista/

Devalle de Rendo, A. y Vega V. (2006). Una escuela en y para la diversidad: El entramado de la diversidad. Buenos Aires: Aique Grupo Editor.

Dos Santos, M. P. y Moreira P. M. (2014). Inclusão em educação: culturas, políticas e práticas. 2da. ed. São Paulo: Cortez Editora.

Echeita, G. (2009). Los procesos de inclusión educativa desde la Declaración de Salamanca. Un balance entre doloroso y esperanzado. En C. Giné (coord.), La educación inclusiva. De la exclusión a la plena participación de todo el alumnado (pp. 25-47). Barcelona: Horsori.

Educación 2020 (2017). Plan Nacional de Educación: 30 prioridades para el 2030. Santiago: Educación 2020. Recuperado de http://educacion2020.cl/sites/ default/files/plan_nacional_de_educacion_2017.pdf

Fernándes Dinis, N. (2011). Homofobia e educação: quando a omissão também é signo de violência. Educar em Revista, (39), 39-50. https://doi.org/10.1590/ S0104-40602011000100004

Fernández, J. (s.f.). Debate sobre educación: inclusión, calidad y juventud rural. El Dinamo. Recuperado de https://www.eldinamo.cl/blog/debatesobre-educacion-inclusion-calidad-y-juventud-rural/ 
Galaz, C. (2012). El señuelo de la integración: Los procesos de diferenciación, subjetivación y subalternización en los dispositivos educativos para las mujeres inmigradas. Revista Latinoamericana de Educación Inclusiva, 6(1), 89-103.

García Huidobro, J. E. (2007). Desigualdad educativa y segmentación del sistema escolar. Consideraciones a partir del caso chileno. Revista Pensamiento Educativo, 40(1), 65-87.

García-Barrera, A. (2017). Las necesidades educativas especiales: un lastre conceptual para la inclusión educativa en España. Ensaio: Avaliação e Política Pública em Educação, 25(96), 721-742. https://doi.org/10.1590/ s0104-40362017002500809

Godoy, M., Meza, M. y Salazar, A. (2004). Antecedentes históricos, presente y futuro de la educación especial en Chile. Santiago: MINEDUC - Programa de Educación Especial. Recuperado de http://portales.mineduc.cl/usuarios/ edu.especial/doc/201304151210180.doc_Antecedentes_Ed_Especial.pdf

Infante, M. (2010). Desafíos a la formación docente: inclusión educativa. Estudios Pedagógicos, XXXVI(1), 287-297. https://doi.org/10.4067/ S0718-07052010000100016

Instituto Nacional de la Juventud - INJUV (2013). Séptima Encuesta Nacional de la Juventud. Santiago: INJUV. Recuperado de http://www.injuv.gob.cl/ portal/wp-content/files_mf/septimaencuestanacionaljuventud2.pdf

Martín, M. y Riaño, M. (2016). Aproximación a los conceptos de asimilación, segregación e integración cultural a través de la composición musical. Revista de educaçâo e humanidades, (10), 215-228.

McManis, L. D. (2017). Inclusive Education: What It Means, Proven Strategies, and a Case Study. Recuperado de https://education.cu-portland.edu/blog/ classroom-resources/inclusive-education/

Manghi, D.; Saavedra, C. y Bacuñán, N. (2018). Prácticas educativas en contextos de educación pública, inclusión más allá de las contradicciones. Revista Latinoamericana de Educación Inclusiva, 12(2), 21-39. https://doi. org/10.4067/S0718-73782018000200021

Mineduc (2012). Orientaciones técnicas para programas de integración escolar (PIE). Santiago: Mineduc. Recuperado de https://especial.mineduc.cl/wp-content/uploads/sites/31/2016/09/Orientaciones-PIE-2013-3.pdf

Mineduc - Centro de Innovación en Educación - Fundación Chile (2013). Análisis de la Implementación de los Programas de Integración Escolar (PIE) en Establecimientos que han incorporado Estudiantes con Necesidades Educativas Especiales Transitorias (NEET). Recuperado de https://especial. mineduc.cl/wp-content/uploads/sites/31/2016/08/Resumen_Estudio_ ImplementacionPIE_2013.pdf 
Mineduc (2015). Diversificación de la enseñanza. Decreto N83/2015 aprueba criterios y orientaciones de adecuación curricular para estudiantes con Necesidades Educativas Especiales de Educación Parvularia y Educación Básica. Santiago: División de Educación General - Unidad de Currículo MINEDUC. Recuperado de file://D:/Decreto\%2083/Decreto-83-2015. pdf

Mineduc (2016). Orientaciones para la construcción de comunidades educativas inclusivas. Recuperado de https://media.mineduc.cl/wpcontent/uploads/ sites/28/2017/07/Orientaciones-Comunidades-EducativasInclusivas.pdf

Narodowski, M. (1999). Después de clases. Desencantos y desafíos de la escuela actual. Buenos Aires: Ediciones Novedades Educativas.

Ocampo, A (2014). Los desafios de la «inclusión» en la educación superior latinoamericana en el siglo XXI. Valparaíso. Recuperado de https://www.senadis. gob.cl/descarga/i/1949/documento

Onrubia, J. (2009). Transformar para adaptar, adaptar para incluir: una mirada psicoeducativa a la educación inclusiva. En C. Giné (coord.), La educación inclusiva. De la exclusión a la plena participación de todo el alumnado (pp. 56-72). Barcelona: Horsori.

Paineo, J. (2012) Antecedentes históricos de la educación especial en Chile. Santiago: Fundación Coanil. Recuperado de http://www.slideshare.net/ JocelynPaineo $1 /$ historia-de-la-educacion-especial-15487382

Rieser, R. (2012). Implementing Inclusive Education A Commonwealth Guide to Implementing Article 24 of the UN Convention on the Rights of Persons with Disabilities. Londres: The Publications Section - Commonwealth Secretariat - Marlborough House - Pall Mall. Recuperado de https:// www.globaldisabilityrightsnow.org/sites/default/files/related-files/346/ Implementing_Inclusive_Education_Article_24_in_CRPD.pdf

Rojas, M. T. y Armijo, M. (2016). Qué es la inclusión escolar: distintas perspectivas en debate. Cuaderno de Educación, (75), 1-11. Recuperado de http://mailing.uahurtado.cl/cuadernos_educacion_75/documentos/articulo_75.pdf

Rubio, F. (2009). Principios de normalización, integración e inclusión. Recuperado de http://educespecialjujuy.xara.hosting/index_htm_files/PRINCIPIO $\% 20$ DE\%20NORMALIZACION,\%20INTEGRACION\%20E\%20 INCLUSION.pdf

Sanhueza, S., Granada, M. y Bravo, L. (2012). Actitudes del profesorado de Chile y Costa Rica hacia la inclusión educativa. Cuadernos de Pesquisa, 42(147), 884-899. https://doi.org/10.1590/S0100-15742012000300013

Santos, M. P. y Moreira, M. P. (2014). Inclusão em Educação. 2da. ed. São Paulo: Cortez Editora. 
Santos, M. P., Santiago, M. C. y Melo, S. C. (2018). Formação de professores frente ao desafio da diversidade pela lente omnilética: culturas, políticas e práticas em movimento. Revista Linhas, 19(39), 11-29. https://doi. org/10.5965/1984723819392018011

Samper, E. (2002). Educación y globalización. En E. Samper y A. Camacho (coords.), Educación y globalización: los desafíos para América Latina (pp. 43-49). Santiago de Chile: Naciones Unidas/CEPAL/ECLAC/OEI.

Sampedro, B. E. y McMullin, K. J. (2015). Videojuegos para la inclusión educativa. Digital Education Review, (27), 122-137.

Sawaia, B. (org.) (1999). As artimanhas da exclusão - analise psicosocial e ética da desigualdade social. Petrópolis: Vozes.

Slee, R. (2012). La escuela extraordinaria. Exclusión, escolarización y educación inclusiva. Madrid: Morata.

Tamayo, M., Carvallo, M., Sánchez, M. y Rebolledo, J. (2018). Programa de Integración Escolar en Chile: brechas y desafíos para la implementación de un programa de educación inclusiva. Revista Española de Discapacidad, 6(I), 161-179 https://doi.org/10.5569/2340-5104.06.01.08

Tenorio, S. (2009). Representaciones sociales de la integración escolar: miradas en tensión. Revista Perspectivas Educacionales, (9), 209-207.

Tenorio, S. (2011). Formación inicial docente y necesidades educativas especiales. Estudios Pedagógicos, XXXVII(2), 249-265. https://doi.org/10.4067/ S0718-07052011000200015

Unesco (2011). Sistema educativo de Chile fomenta la desigualdad. Santiago: OREALC/Unesco. Recuperado de http://portal.unesco.org/geo-

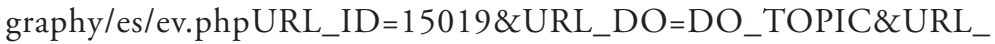
SECTION=201.html

Unesco (2012). Respuestas del sector educación frente al bullying homofóbico. Cuadernillo 8. París: Unesco. Recuperado de http://www.unesco.org/new/ fileadmin/MULTIMEDIA/FIELD/Havana/pdf/Educacion_bullying.pdf

Unesco - PRELAC- Secretaria de Educación Pública México (2013). Situación educativa de América Latina y el Caribe. Hacia una educación para todos 2015. Santiago: Unesco. Recuperado de http://www.unesco.org/new/ fileadmin/MULTIMEDIA/FIELD/Santiago/pdf/situacion-educativamexico-2013.pdf

Unicef (2012). La exclusión educativa un desafio urgente para Chile. Recuperado de https://especial.mineduc.cl/wp-content/uploads/sites/31/2016/08/ Resumen_Estudio_ImplementacionPIE_2013.pdf 
Valladares, M. A. (2013). Tensiones entre las prácticas pedagógicas y los desafíos de la formación inicial docente desde la perspectiva de la educación inclusiva. Revista Latinoamericana de Educación Inclusiva, 6(1), 153-175.

Verdugo, M. A., Amor, A. M., Fernández, M., Navas, P. y Calvo, I. (2018). La regulación de la inclusión educativa del alumnado con discapacidad intelectual: una reforma pendiente. Siglo Cero, 49(2), 27-58. https://doi. org/10.14201/scero20184922758

Villalobos, C. (2014). Fin a la selección en el sistema escolar. Elementos para su comprensión y aplicación. Recuperado de https://www.elmostrador.cl/ noticias/opinion/2014/05/06/fin-a-la-seleccion-en-el-sistema-escolar-elementos-para-su-comprension-y-aplicacion/

Williamson, G. y Díaz, M. (2015). Interculturalidade no Ensino Superior: açôes e reflexôes desde os direitos humanos. Conjectura, 20, 101-130. 